\title{
PENGENALAN KONSEP BERAT-RINGAN BENDA MENGGUNAKAN PEMBELAJARAN LANGSUNG UNTUK MENINGKATKAN KEMAMPUAN BERHITUNG ANAK TUNARUNGU KELAS I DI SLB NEGERI CERME GRESIK
}

\author{
Juli Setyaningsih \\ SLB Negeri Cerme Gresik \\ julokebraon@gmail.com
}

\begin{abstract}
Abstrak
Penelitian ini bertujuan untuk mendeskripsikan tingkat kemampuan mengenal konsep berat-ringan benda siswa tunarungu dengan menggunakan pembelajaran langsung. Penelitian ini terdiri dari dua siklus yang melibatkan siswa kelas I B semester 1 SLB Negeri Cerme Gresik tahun pelajaran 2016/2017. Penelitian ini menggunakan instrumen berupa lembar observasi dan tes tulis dan observasi dilakukan pada setiap proses pembelajaran. Hasil penelitian menunjukkan bahwa pada siklus I diperoleh nilai ratarata hasil belajar sebesar 55\%. Pada siklus ke II terjadi peningkatan dan diperoleh nilai rata-rata hasil belajar sebesar $80,13 \%$. Hal ini mengindikasikan bahwa penggunaan pembelajaran langsung dapat meningkatkan kemampuan mengenal konsep beratringan benda pada siswa tunarungu kelas I SLB Negeri Cerme Gresik Tahun Pelajaran 2016/2017.
\end{abstract}

Kata Kunci: pembelajaran langsung, konsep berat-ringan benda, siswa tunarungu

\section{PENDAHULUAN}

Pendidikan merupakan salah satu indikator penting dalam memajukan suatu bangsa. Karena dengan melalui pendidikan, kehidupan suatu bangsa dapat terangkat harkat dan martabatnya. Pendidikan perlu diikuti oleh setiap warga negara tanpa terkecuali, salah satunya adalah anak tunarungu (Zusfindhana, 2020).
(Badiah, Jauhari, \& Mambela, 2020) mengungkapkan bahwa yang dimaksud dengan anak tunarungu adalah anak yang tidak atau kurang mampu mendengar suara. Anak tunarungu yang mengalami kesulitan terutama dalam mengenal konsep berat-ringan benda disebabkan gangguan pada pendengaran, sehingga prestasi akademik anak tunarungu cenderung 
tertinggal dibandingkan dengan anak normal (Soemantri, 2006)

\section{Dalam Kamus Umum Bahasa} Indonesia dijelaskan bahwa kemampuan berasal dari kata mampu yang berarti kuasa melakukan sesuatu, sedangkan arti dari kata kemampuan adalah kesanggupan untuk melakukan sesuatu. Dengan demikian, kemampuan mengenal konsep beratringan benda adalah kesanggupan atau kecakapan anak dalam mengetahui dan membedakan benda yang banyak tekanannya apabila ditimbang dan benda yang sedikit tekanannya apabila ditimbang (Fefrian, Mardhika, Santika, \& Sumardi, 2020).

Berdasarkan studi pendahuluan melalui observasi selama belajar di SLB Negeri Cerme Gresik peneliti menemukan anak tunarungu di kelas I yang berjumlah 4 anak mengalami kesulitan dalam mengenal konsep beratringan benda. Hal ini terlihat ketika dalam pembelajaran di kelas, masingmasing anak tunarungu mengalami kesulitan dalam membedakan konsep berat-ringan benda.
Metode pembelajaran langsung untuk mengenalkan konsep beratringan benda memiliki keunggulan antara lain: 1) guru mengendalikan isi materi dan urutan informasi yang diterima oleh anak 2) merupakan metode yang efektif untuk mengajarkan konsep yang eksplisit kepada anak 3) untuk membangun pembelajaran dalam bidang studi tertentu, 4) guru dapat menunjukkan bahwa bagaimana suatu permasalahan dapat didekati, bagaimana informasi dianalisis, bagaimana suatu pengetahuan dihasilkan, dan 5) pembelajaran langsung dapat memberikan tantangan untuk mempertimbangkan kesenjangan antara teori dan observasi (Jauhari, Irvan, \& Sakre, 2017).

Berdasarkan permasalahan di atas maka, pembelajaran mengenal konsep berat-ringan benda diberikan pada anak tunarungu SLB Negeri Cerme Gresik menggunakan pembelajaran langsung.

\section{METODE PENELITIAN}

Subjek penelitian ini adalah siswa tunarungu kelas I SLB Negeri Cerme Gresik yang berjumlah 4 siswa 
tunarungu. Masing-masing siswa mengalami kesulitan dalam mengenal konsep berat-ringan benda. Penelitian dilakukan di SLB Negeri Cerme Gresik yang berlokasi di Jalan Jurit Cerme Kidul, Kabupaten Gresik. Penelitian ini dilaksanakan pada bulan September 2016 dalam dua siklus dengan satu siklus terdiri dari dua kali pertemuan dan satu kali pertemuan berdurasi 60 menit.

Rancangan dalam penelitian ini direncanakan menggunakan desain model Hopkins (dalam Arikunto, 2006) yang digambarkan suatu proses yang meliputi aspek perencanaan, tindakan, observasi, dan refleksi. Rancangan penelitian tindakan ini dilakukan oleh guru siswa tunarungu kelas I.

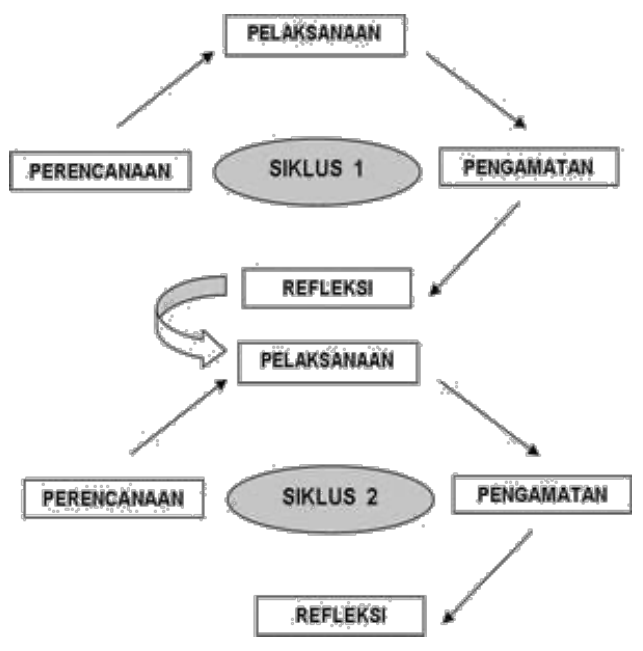

Gambar 1. Alur PTK
Teknik pengumpulan data yang digunakan dalam penelitian ini yaitu menggunakan tes tulis, observasi, dan dokumentasi. Data lembar observasi digunakan untuk mengetahui pengaruh pembelajaran langsung dan data diperoleh dari pengamatan kinerja siswa dalam memahami materi dan kinerja guru dalam menguasai pembelajaran langsung.

Untuk menemukan tingkat keberhasilan pemberian tindakan pada anak tunarungu di SLB Negeri Cerme Gresik, maka peneliti menargetkan tingkat keberhasilan yang harus dicapai oleh masing-masing anak adalah 75\% dan analisis data yang digunakan dalam penelitian ini adalah analisis refleksi berdasarkan siklus-siklus.

\section{HASIL DAN PEMBAHASAN}

Sebelum peneliti memberikan tindakan kepada anak melalui pembelajaran langsung, terlebih dahulu peneliti mengukur kemampuan awal anak. Hal ini dilakukan untuk mengetahui seberapa besar kemampuan mengenal konsep berat-ringan benda 
sebelum diberikan pembelajaran langsung. Hasil penilaian kemampuan awal anak terdapat pada tabel 1.

Tabel 1. Hasil penilaian kemampuan awal anak (prasiklus)

\begin{tabular}{|c|c|c|c|c|c|}
\hline \multirow{2}{*}{ No } & \multirow{2}{*}{ Aspek Yang Dinilai } & \multicolumn{4}{|c|}{ Nilai (\%) } \\
\hline & & $\mathbf{A H}$ & JS & MZ & EB \\
\hline 1 & Pemahaman konsep & 2 & 1 & 1 & 1 \\
\hline 2 & $\begin{array}{l}\text { Mengukur dan } \\
\text { membandingkan berat- } \\
\text { ringan benda }\end{array}$ & 2 & 2 & 1 & 2 \\
\hline 3 & $\begin{array}{l}\text { Membedakan berat- } \\
\text { ringan benda }\end{array}$ & 2 & 2 & 2 & 1 \\
\hline & Jumlah & 6 & 5 & 4 & 4 \\
\hline \multicolumn{2}{|c|}{$\begin{array}{c}\text { Nilai }=\frac{\text { skor yang diperoleh }}{\text { skor maksimum }} \\
\times 100 \%\end{array}$} & $50 \%$ & $42 \%$ & $33 \%$ & $33 \%$ \\
\hline & Rata-rata & \multicolumn{4}{|c|}{$39,5 \%$} \\
\hline
\end{tabular}

Dari tabel 1, dapat dilihat bahwa kemampuan anak dalam mengenal konsep berat-ringan masih sangat kurang. Dengan demikian, dengan menggunakan pembelajaran langsung, kemampuan siswa dalam mengenal konsep berat-ringan akan meningkat.

Pada siklus I, proses belajar mengajar berjalan sesuai dengan rencana pembelajaran yang telah dirumuskan. Dapat dilihat pada tabel 2, nilai rata-rata hasil belajar menunjukkan peningkatan yang signifikan. Namun, peran guru dalam proses pembelajaran masih dominan karena tingkat partisipasi siswa yang masih kurang. Dengan demikian, strategi pembelajaran pada siklus II perlu diubah dengan cara pembelajaran lebih ditekankan pada penerapan di kehidupan sehari-hari dan pemberian hadiah pada siswa yang memperoleh hasil yang bagus sehingga siswa lebih aktif dan antusias dalam mengikuti pembelajaran.

\begin{tabular}{|c|c|c|c|c|c|c|c|c|c|}
\hline \multirow{3}{*}{ No } & \multirow{3}{*}{ Aspek Yang Dinilai } & \multicolumn{8}{|c|}{ Nilai (\%) } \\
\hline & & \multicolumn{4}{|c|}{ Pertemuan 1} & \multicolumn{4}{|c|}{ Pertemuan 2} \\
\hline & & $\mathbf{A H}$ & JS & MZ & EB & $\mathbf{A H}$ & JS & MZ & EB \\
\hline 1 & Pemahaman konsep & 2 & 2 & 2 & 1 & 3 & 2 & 2 & 2 \\
\hline 2 & $\begin{array}{l}\text { Mengukur dan } \\
\text { membandingkan berat-ringan } \\
\text { benda }\end{array}$ & 3 & 2 & 1 & 2 & 3 & 2 & 3 & 2 \\
\hline 3 & $\begin{array}{l}\text { Membedakan berat-ringan } \\
\text { benda }\end{array}$ & 2 & 2 & 2 & 2 & 2 & 3 & 2 & 2 \\
\hline & Jumlah & 7 & 6 & 5 & 5 & 8 & 7 & 7 & 6 \\
\hline & $\mathrm{ai}=\frac{\text { skor yang diperoleh }}{\text { skor maksimum }} \times 100 \%$ & $58 \%$ & $50 \%$ & $42 \%$ & $42 \%$ & $67 \%$ & $58 \%$ & $58 \%$ & $50 \%$ \\
\hline & Rata-rata & \multicolumn{4}{|c|}{$48 \%$} & \multicolumn{4}{|c|}{$58,3 \%$} \\
\hline
\end{tabular}

Peran guru dalam siklus I menunjukkan nilai yang kurang baik karena pembelajaran masih baru dan belum terbentuk adanya koneksi yang kuat antara guru dan siswa. Hasil observasi guru dalam mengenal konsep berat-ringan benda melalui pembelajaran langsung pada siklus I terdapat pada Tabel 3. 
Tabel 3. Hasil observasi guru dalam mengenal konsep berat-ringan benda melalui pembelajaran langsung pada siklus I

\begin{tabular}{|c|c|c|c|c|c|c|c|c|c|}
\hline \multirow{3}{*}{ No } & \multirow{3}{*}{ Aspek yang diobservasi } & \multicolumn{8}{|c|}{ Hasil } \\
\hline & & \multicolumn{4}{|c|}{ Pertemuan 1} & \multicolumn{4}{|c|}{ Pertemuan 2} \\
\hline & & 1 & 2 & 3 & 4 & 1 & 2 & 3 & 4 \\
\hline 1 & $\begin{array}{l}\text { Persiapan: } \\
\text { - Menyampaikan tujuan dan mempersiapkan } \\
\text { anak }\end{array}$ & & & $\checkmark$ & & & & $\checkmark$ & \\
\hline 2 & $\begin{array}{l}\text { Pelaksanaan: } \\
\text { - Mendemonstrasikan keterampilan atau } \\
\text { mempresentasikan pengetahuan } \\
\text { - Membimbing pelatihan } \\
\end{array}$ & & $\checkmark$ & & & & $\checkmark$ & $\checkmark$ & \\
\hline 3 & $\begin{array}{l}\text { Evaluasi : } \\
\begin{array}{l}\text { - Mengecek pemahaman dan memberi umpan } \\
\text { balik berupa tes tulis }\end{array}\end{array}$ & & $\checkmark$ & & & & & $\checkmark$ & \\
\hline 4 & $\begin{array}{l}\text { Pembahasan: } \\
\text { - Memberikan kesempatan untuk pelatihan } \\
\text { lanjutan dan penerapan }\end{array}$ & & $\checkmark$ & & & & $\checkmark$ & & \\
\hline & Jumlah & & 1 & & & & & 3 & \\
\hline & Nilai $=\frac{\text { skor yang diperoleh }}{\text { skor maksimum }} \times 100 \%$ & & 55 & & & & & $5 \%$ & \\
\hline
\end{tabular}

Pembelajaran pada siklus II menunjukkan perkembangan yang baik. Proses belajar mengajar sudah berjalan sesuai dengan rencana dan siswa sudah dapat memahami apa yang dijelaskan oleh guru. Selain itu, suasana kelas menjadi suasana yang hidup dan kondusif dan siswa lebih aktif dalam melakukan pembelajaran (Jauhari, n.d.) dan (Rafikayati \& Jauhari, n.d.). Hasil penilaian pembelajaran dan Hasil observasi guru dalam mengenal konsep berat-ringan benda melalui pembelajaran langsung pada siklus I terdapat pada Tabel 4 dan 5 .

\begin{tabular}{|c|c|c|c|c|c|c|c|c|c|}
\hline \multirow{3}{*}{ No } & \multirow{3}{*}{ Aspek Yang Dinilai } & \multicolumn{8}{|c|}{ Nilai (\%) } \\
\hline & & \multicolumn{4}{|c|}{ Pertemuan 1} & \multicolumn{4}{|c|}{ Pertemuan 2} \\
\hline & & AH & JS & MZ & EB & $\mathbf{A H}$ & JS & MZ & EB \\
\hline 1 & \begin{tabular}{|l|} 
Pemahaman konsep \\
\end{tabular} & 3 & 3 & 3 & 2 & 3 & 3 & 3 & 3 \\
\hline 2 & $\begin{array}{l}\text { Mengukur dan } \\
\text { membandingkan berat- } \\
\text { ringan benda }\end{array}$ & 4 & 3 & 3 & 3 & 4 & 4 & 3 & 4 \\
\hline 3 & $\begin{array}{l}\text { Membedakan berat- } \\
\text { ringan benda }\end{array}$ & 3 & 3 & 3 & 3 & 4 & 3 & 4 & 3 \\
\hline \multicolumn{2}{|r|}{ Jumlah } & 10 & 9 & 9 & 8 & 11 & 10 & 10 & 10 \\
\hline \multicolumn{2}{|r|}{ 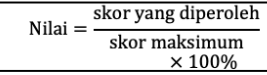 } & $83 \%$ & $75 \%$ & $75 \%$ & $67 \%$ & $92 \%$ & $83 \%$ & $83 \%$ & $83 \%$ \\
\hline & Rata-rata & \multicolumn{4}{|c|}{$75 \%$} & \multicolumn{4}{|c|}{$85,3 \%$} \\
\hline
\end{tabular}

\begin{tabular}{|c|c|c|c|c|c|c|c|c|c|}
\hline \multirow{3}{*}{ No } & \multirow{3}{*}{ Aspek yang diobservasi } & \multicolumn{8}{|c|}{ Hasil } \\
\hline & & \multicolumn{4}{|c|}{ Pertemuan 1} & \multicolumn{4}{|c|}{ Pertemuan 2} \\
\hline & & 1 & 2 & 3 & 4 & 1 & 23 & & 4 \\
\hline 1 & $\begin{array}{l}\text { Persiapan: } \\
\text { - Menyampaikan tujuan dan mempersiapkan } \\
\text { anak }\end{array}$ & & & & $\checkmark$ & & & & $\checkmark$ \\
\hline 2 & $\begin{array}{l}\text { Pelaksanaan : } \\
\text { - Mendemonstrasikan keterampilan atau } \\
\text { mempresentasikan pengetahuan } \\
\text { - Membimbing pelatihan }\end{array}$ & & $\checkmark$ & $\checkmark$ & & & & & \\
\hline 3 & $\begin{array}{l}\text { Evaluasi : } \\
\begin{array}{l}\text { - Mengecek pemahaman dan memberi umpan } \\
\text { balik berupa tes tulis }\end{array}\end{array}$ & & & $\checkmark$ & & & & & \\
\hline 4 & $\begin{array}{l}\text { Pembahasan: } \\
\text { - Memberikan kesempatan untuk pelatihan } \\
\text { lanjutan dan penerapan }\end{array}$ & & $\checkmark$ & & & & & & \\
\hline & Jumlah & \multicolumn{4}{|c|}{14} & \multicolumn{4}{|c|}{16} \\
\hline & Nilai $=\frac{\text { skor yang diperoleh }}{\text { skor maksimum }} \times 100 \%$ & \multicolumn{4}{|c|}{$70 \%$} & \multicolumn{4}{|c|}{$80 \%$} \\
\hline
\end{tabular}

Implementasi pembelajaran langsung yang digunakan untuk pengenalan konsep berat-ringan pada siswa tunarungu kelas I SLB Negeri Cerme Gresik semester 1 tahun pelajaran 2016/2017, ternyata lebih efektif dalam meningkatkan dan menumbuhkan aktivitas, motivasi dan prestasi belajar siswa. Dengan diberikannya pembelajaran langsung pada anak tunarungu, diharapkan dapat meningkatkan kemampuan mengenal konsep berat-ringan benda. Adapun rekapitulasi hasil penilaian kemampuan mengenal konsep berat-ringan benda siklus I dan siklus II terdapat pada Gambar 2. 


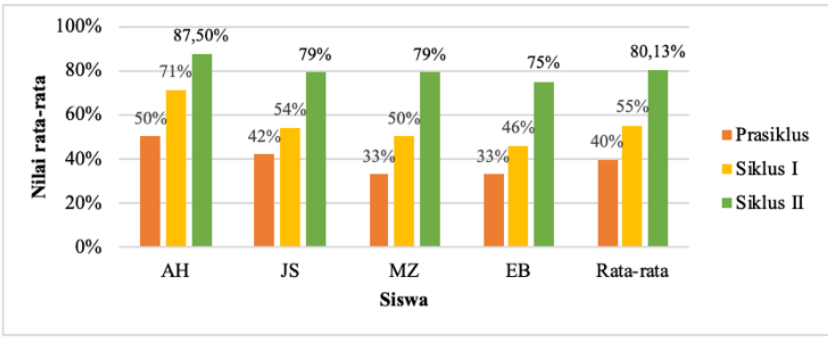

Gambar 2. Rekapitulasi perkembangan kemampuan mengenal konsep berat-ringan benda siklus I dan siklus II

Berdasarkan nilai yang dicapai pada siklus I dan siklus II bahwa kemampuan mengenal konsep beratringan benda anak tunarungu SLB Negeri Cerme Gresik dapat meningkat melalui pembelajaran langsung. Peningkatan ini bukanlah untuk selamanya tetapi hanya untuk sementara jika kemampuan mengenal konsep berat-ringan benda anak dilatih secara berulang-ulang akan mendapatkan hasil yang optimal.

\section{KESIMPULAN}

Berdasarkan hasil penelitian dan pembahasan dengan memperhatikan tujuan penelitian, dapat disimpulkan sebagai berikut. Pembelajaran langsung merupakan salah satu pembelajaran yang dapat digunakan untuk meningkatkan kemampuan mengenal konsep berat-ringan benda anak tunarungu di SLB Negeri Cerme Gresik.
Dalam penelitian tindakan ini terjadi peningkatan kemampuan mengenal konsep berat-ringan benda pada siswa tunarungu yang ditunjukkan dalam siklus I dan siklus II, yaitu mencapai nilai rata-rata sebesar $55 \%$ pada siklus I dan meningkat menjadi $80,13 \%$ pada siklus II.

Mengacu pada simpulan di atas, maka diajukan beberapa saran yaitu: 1) agar aktivitas anak tunarungu meningkat, sebaiknya temuan penelitian ini dapat diimplementasikan sebagai referensi oleh guru kelas dengan menggunakan pembelajaran langsung sebagai proses untuk memperbaiki sikap anak terhadap pelajaran matematika dan 2) diperlukan penerapan pembelajaran langsung secara berulang agar siswa menjadi terbiasa dan memperoleh hasil yang optimal (Badiah, 2020).

\section{DAFTAR PUSTAKA}

Arikunto, S. dkk. 2007. Penelitian Tindakan Kelas. Jakarta: Bumi Aksara

Badiah, L. I. (2020). Studi Deskriptif Implementasi Kurikulum 2013 Untuk 
Anak Tunarungu Tingkat Sekolah Dasar. Didaktis: Jurnal Pendidikan Dan Ilmu Pengetahuan, 20(2).

Badiah, L. I., Jauhari, M. N., \& Mambela, S. (2020). Penerapan Pelatihan Terapi Auditory Verbal Therapy (AVT) untuk Mengembangkan Kemampuan Bahasa Anak Tunarungu. Jurnal ORTOPEDAGOGIA, 6(1), 39-42.

Fefrian, Y., Mardhika, R., Santika, R. H., \& Sumardi, S. (2020). Penjas Adaptif Bagi Guru Sekolah Luar Biasa (SLB) Siswa Budhi Surabaya. SPEED Journal: Journal of Special Education, 3(2), 101-106.

Jauhari, M. N. (n.d.). Pengembangan Simbol Signalong Indonesia Sebagai Media Komunikasi Anak Berkebutuhan Khusus. Jauhari, M. N., Irvan, M., \& Sakre, T. (2017). Communication Of Children With Special Needs Using Signalong Indonesia. International Conference On Education, 1(1).

Rafikayati, A., \& Jauhari, M. N. (n.d.). Studi tentang Pelaksanaan Pelatihan Terapi Wicara Anak Tunarungu Usia 3-5 Tahun untuk Orangtua dalam Setting Blended Learning di SLB Karya Mulia Surabaya.

Zusfindhana, I. H. (2020). Peningkatan Kemampuan Perkalian 10-20 melalui Metode Jarimatika Pada Siswa Tunarungu di SLB-B dan Autis TPA
Jember. SPECIAL: Special and Inclusive Education Journal, 1(1), 37-43. 